\title{
Criteria Affecting Pre-service TESOL Teachers' Attitudes towards Using CD-ROM Dictionaries
}

\author{
Jinan Hatem Issa (Corresponding author) \\ School of Educational Studies, Universiti Sains Malaysia \\ 3B-24-07, N-Park Condominium, Jalan Batu Uban, 11700, Gelugor, Pulau Pinang, Malaysia \\ Tel: 60-17-3684125Ｅ-mail: jinanfiras@hotmail.my
}

Hazri Jamil

School of Educational Studies, Universiti Sains Malaysia

11800 USM, Pulau Pinang, Malaysia

Tel: 60-12-4735019Ｅ-mail: hazri@usm.my

Received: September 29, 2011

Accepted: April 11, 2012

Published: May 1, 2012

doi:10.5539/elt.v5n5p118

URL: http://dx.doi.org/10.5539/elt.v5n5p118

The research is facilitated and supported by Universiti Sains Malaysia (USM)

\begin{abstract}
Undoubtedly, CD-ROM dictionaries assist in removing the fear of inadequacy in language usage and ameliorating the panic of being-on-the-spot especially with the rapid development of information technology. This research was conducted to find out whether there is a relationship between pre-service TESOL teachers' attitudes towards using CD-ROM dictionaries and certain criteria (perceived usefulness, perceived ease of use, functions and multimedia content). The theoretical framework for the study was drawn from TAM model. A modified questionnaire was utilised with employing a mixed-method approach using two sampling techniques (Purposive and Random) to pre-service TESOL teachers. The finding exposed a positive significant correlation between attitudes towards using CD-ROM dictionaries and criteria. A further finding exhibited that the CD-ROM dictionaries do assist learning the four main language skills (reading, writing, listening and speaking) and the subsidiary skills (grammar, punctuation and pronunciation).
\end{abstract}

Keywords: CD-ROM dictionary, Pre-service TESOL teachers, Attitudes, Criteria

\section{Introduction}

Over the past several decades, the revolution of information and communication technologies (ICTs) has introduced different forms of potentially powerful enabling tools in acquiring English as a second language for educational change and reform such as CD-ROM dictionaries (Tinio, 2003). A CD-ROM dictionary is an interesting and effective teaching tool that captures pre-service teachers' interest and does much more than just translates. Using CD-ROM dictionaries in acquiring the new language is believed to be beneficial because it allows individual mental resources to develop and provides opportunities for language learners to explicitly focus on form while expressing their intended meaning as accurately and as coherently as possible (Koyama \& Takeuchi, 2007).

A new trend has recently appeared to using CD-ROM in acquiring the new language especially after the introduction of ICT in classes. Recently, learning English through computer assisted instruction and becoming computer literate through learning English is the trend in many ESL/EFL learning and teaching programs (Nguyen, 2008). After utilising electronic dictionaries, in general, and CD-ROM dictionaries, in particular, in conducting English lessons in any educational environment, Proficiency in English verifies very useful and those who have a good command over the language do very well (De-Schryver, 2003; De-Schryver \& Joffe, 2004).

In fact, learners are often reluctant to use monolingual dictionaries because they think they will be difficult to understand. Classroom activities can help learners become more comfortable with using dictionaries on their own. Learners cannot make full use of their dictionaries; however, unless they know how to use them and are motivated to do so (Winkler, 2001). A vital part of learner training and teaching dictionary skills is referencing skills which 
should not be a one-off lesson or activity, but an on-going process of working together with students when vocabulary issues crop up (Moore, 2005). Similarly, Liou (2000) wrote that little is known about how learners make use of dictionaries to understand texts.

During the pre-service education program, the pre-service teachers will learn how to use their knowledge to make lesson plans to teach their classes. They are given common topics include classroom management, lesson plans, and professional development. During the period of such education programs, a major focus is the practicum where the pre-service teacher is placed within a school setting (either elementary or senior) and shadows an experienced teacher. Besides, they will be given opportunities to develop skills through lesson plans, teaching lessons and classroom management (Le Cornu \& Ewing, 2008). Pre-service teaching, according to Brog (2007), is a process of supervised and guided teaching to benefit teachers' professional growth and pedagogical activity. Therefore, pre-service teachers are expected to progressively adapt themselves from being knowledge receivers into knowledge presenters and ultimately into knowledge facilitators in technology based classroom and hence teachers will have new roles to play that are different from the conventional classroom teaching practices that they were used to (Shelly, Cashman, Cashman, Gunter, \& Gunter, 2007).

The field of social psychology has considered in depth attitude as a concept; the construct of attitude is complex and multi-dimensional. Although lots of researches have been done on learners' attitudes towards language learning and some towards using electronic dictionaries but little research can be found on pre-service teachers' attitudes towards using CD-ROM dictionaries or its criteria (perceived usefulness, perceived ease of use, functions and multimedia contents) especially in the Malaysian context. Hence, this study seeks to achieve two explicit objectives; firstly, to find out whether there is a relationship between pre-service TESOL teachers' attitudes towards using CD-ROM dictionaries and certain criteria (perceived usefulness, perceived ease of use, functionality and multimedia content) identified as potentially influencing those attitudes; and secondly, to explore the learning needs that pre-service TESOL teachers utilise CD-ROM dictionaries for.

\section{Materials and Method}

Due to the fact that English language now becomes a global language and despite the extraordinary changes of the last few years, one thing appears to remain the same, more people than ever want to learn English. Therefore, the 21 st century is marked by an ever-increasing number of English learners versus decreasing in their ages (Graddol, 2006). Not surprisingly, social scientists and educationists are well aware of the language importance and agree that a student should learn English to excel in his/her life. However, a problem encounters the learner in the process of learning a language which is the enhancement of one's vocabulary. Therefore, most students, to offset this difficulty, purchase dictionaries to build up their vocabulary (Wright, 1998). Some teachers may recommend a few paper dictionaries to their students ignoring the different types available of electronic dictionaries like the pocket electronic dictionary or the CD-ROM dictionary or even the online dictionary. Despite the fact that a paper dictionary takes much time and the concentration of a person can be broken while reading, it cannot be carried everywhere as well. Thus, learners do not receive enough advice to make the right choice when considering the selection of a resource for a particular task or the purchase of a dictionary (Pasfield-Neofitou, 2009).

Actually, no one can deny the fact that success and enjoyment are the biggest motivators for learners. However, using a dictionary for the mere purpose of looking up the meaning of a word is insufficient especially with the available activities for the different levels of learners to make the process of acquiring new vocabularies a more interesting one. Yet, most if not all, teachers do not seek for developing that important aspect of language learning which is using the dictionary (Moore, 2005). Prior to the lack of studies regarding this issue in the Malaysian context except two on electronic dictionaries (Tan, 2003; Tan \& Woods, 2008); however, there is not any on the CD-ROM dictionary. Studies on CD-ROM dictionaries are very little in general and studies on pre-service TESOL teachers' attitudes towards this specific type of ICT have seldom been researched in particular.

Among the several studies, that investigated electronic and paper dictionaries, was a study conducted in Hong Kong and Taiwan by Hua-Li, Sandnes, Law, Yo-Ping, and Yueh-Min (2009) addressing engineering and humanities students at both undergraduate and graduate levels about the role of electronic pocket dictionaries as a language learning tool. It found out that speed of reference was the main motivator for using an electronic pocket dictionary. Functionality came in the second place. Multimedia content was ranked least important. Another study was carried out by Kusmayanti and Hendryanti (2008) whose results exhibited that electronic dictionaries are used by both teachers and students. The collected data, which were based on the findings of questionnaires and interviews with 30 English teachers and 300 students of junior high schools in West Java, Indonesia, showed that 90 per cent of the English teachers use electronic dictionaries, whilst the rest 10 per cent install dictionary software in their PC from various national and international publishers. It was revealed that 60 per cent of the students use electronic 
dictionary and others use non-electronic dictionary. The problems faced by teachers and students were related to word meaning and usage. The results also showed that using electronic dictionary was futile when they needed to find information about word class, phonetic symbol, antonym, synonym, and examples of sentences as well. The authors concluded that most junior high school teachers and students use electronic dictionary with the cheapest price and simplest features to help them in the teaching and learning process of English language.

In the same respect, Weschler and Pitts (2000) carried out an experiment to find out whether electronic dictionaries are faster to use than paper dictionaries. The sample was a first year English conversation class students. By dividing the class into two groups; a paper bilingual dictionary was given to each student in the PD group and an electronic dictionary to each student in the ED group. A questionnaire was distributed to find out whether students are taking full advantage of their electronic dictionaries. The results showed that students could look up words about 23 per cent faster with an ED. The paper concluded that the earliest computer assisted language learning packages were little more than textbooks on a small screen. However, the researchers stated that electronic dictionaries are still fundamentally paper dictionaries on a microchip. Although electronic dictionaries have certain unique functions, such as cross-referencing (e.g. synonyms and antonyms), word and spelling games, and they are probably faster to use; yet some people simply prefer the feel and legibility of paper. Similarly, Koyama and Takeuchi (2007) found out in their study that EFL learners have looked up at electronic dictionaries (EDs) to comprehend the text in a shorter period of time than those looked up in the printed dictionaries (PDs). Results showed that increased look-up frequency by EFL learners did not guarantee the improvement of reading comprehension.

Regarding criteria (Perceived usefulness, perceived ease of use, functionality and multimedia contents), there was a study conducted by Arning and Ziefle (2007) exploring the attitudes towards a certain technology and the performance when using it especially interacting with a computer simulated PDA device. The results exhibited that there were significant associations between performance and TAM factors. However, this interrelation was much stronger between performance and the ease of use, whereas computer expertise and technical self-confidence played a minor role.

The theoretical framework for this study was drawn from Diffusion of Innovations' Theory by Rogers (1995). Over time in order to elucidate the adoption of innovations such as information technology, Rogers' theory has been utilised by a wide range of researchers and is employed to steer this study illustrating that teacher's adoption of information technology could be better explained in the context of Diffusion of Innovations' Theory which describes the innovation-decision process as an information-seeking and information-processing activity in which an individual obtains information in order to decrease uncertainty about the innovation. Rogers' Innovation Decision Process theory documented that an innovations' diffusion is a process that happens over time via five stages: knowledge, persuasion, decision, implementation and confirmation. First in the knowledge stage, after an initial exposure to innovation potential adopters ought to be knowledgeable about the innovation via several communication channels; next in the Persuasion Stage those individuals are interested in the innovation and actively seek detailed information about the innovation (i.e. they ought to be persuaded of the value of the innovation). Later in the Decision Stage, they take the concept of the innovation and weigh the advantages/disadvantages of using the innovation and decide whether to adopt or reject the innovation. Due to the individualistic nature of this stage, Rogers realised that it is the most difficult stage to acquire empirical evidence. Consequently in the Implementation Stage, the individual employs the innovation to a varying degree depending on the situation; during this stage the individual determines the usefulness of the innovation and may search for further information about it. Finally in the Confirmation Stage, the individual finalises their decision to continue using the innovation and may use the innovation to its fullest potential (i.e. the decision ought to be reconfirmed or abandoned).

A mixed method was applied in this descriptive study by utilising two instruments; a modified questionnaire and a semi-structured interview. Gay, Mills and Airasian (2009), stated that descriptive data are usually collected by questionnaire, interview, telephone, or observation. Hence, the study utilised a combination of quantitative and qualitative approaches defined over two main stages. The first stage involved a distribution of a modified questionnaire to collect the desired date and then an analysis to the collected data. The results of the quantitative analysis were supplemented by in-depth interviews. Interviews as a qualitative element were employed to gather more in-depth information and ensure the trustworthiness of the results which represents the second stage. After collecting the in-depth data from the interviews, transcription procedures were used to analyse the collected data. Finally, interpretation procedures were utilised. Basically, the hypothesis was tested at the significance levels of 0.01 $(a=.01)$ :

$\mathbf{H}_{\mathbf{0}} \mathbf{1}$ : There is no significant relation between criteria and pre-service TESOL teachers' attitudes towards using CD-ROM dictionaries. 
For the purpose of this study, the researcher employed a modified questionnaire via adapting some statements from previous studies based on their relevance to the current study (Sobkowiak, 2002; Weschler \& Pitts, 2000; Winkler, 2001; Yoon \& Hirvela, 2004) mainly used for collecting data about criteria affecting attitudes towards using CD-ROM dictionaries among pre-service TESOL teachers in the School of Educational Studies. Thirty participants were selected randomly for the purpose of the pilot study and another 50 students were chosen randomly for factor analysis purpose to fulfil the reliability of the quantitative instrument represented by the questionnaire. Similarly, the questions for the semi-structured interviews were pilot tested on 2 students who were selected randomly before commencing the process of conducting the interviews.

The ethical process took around three weeks. The instruments were validated by a panel of experts represented by three university lecturers whose major specialisation was teaching English to speakers of other languages and one of them minor specialisation was Information and communication Technology. Moreover, year one, two and three pre-service TESOL Teachers, at the School of Educational Studies, were used as a sample for the study. Therefore, the dean of the School of Educational studies was informed by a letter in which the researcher explained about the research title, purpose of the study and the target sample in order to be permitted to collect the desired data by distributing the modified questionnaire and conducting semi-structured interviews. Furthermore, all the interviewees received invitation letters requesting them to participate in the interviews. In addition to that, all of the interviewees signed consent forms for interviews and handed these over to the interviewer before recording the interviews.

For the purpose of examining the internal consistency of the modified instrument, the results of the pilot study, (see tables1\&2), indicated an overall reliability for Cronbach's Alpha coefficient (0.878) considered as ideal (Nunnally, 1978; Pallant, 2005). On the other hand, factor analysis for Criteria items and Attitude items were assessed via conducting two statistical measures by the Statistical Package of Social Science (SPSS) version .15 to help assess the factorability of the data: Barlett's test of sphericity and the Kaiser-Meyer-Olkin (KMO) measure of sampling adequacy. Table 3 shows that the Barlett's test of sphericity was significant $(p 0.000<0.05)$ which means that the factor analysis is considered appropriate (Tabachnick \& Fidell, 2007). The KMO was 0.60 suggested as the minimum value for a good factor analysis (Kaiser, 1970, 1974; Tabachnick \& Fidell, 2007). Thus, the results of this analysis support the use of items about criteria. Similarly, the 20 items of attitudes were subjected to principal components analysis (PCA). The Kaiser-Meyer-Oklin value was 0.81, (see Table 4), exceeding the recommended value of 0.6 (Kaiser, 1970, 1974) and the Barlett's Test of Sphericity (Barlett, 1954; Dongsheng, Jiahua, Peide, \& Yaohua, 2005) reached statistical significance, supporting the factorability of the correlation matrix. Therefore, the results of this analysis support the use of items about attitudes.

A purposive sampling technique was used to get the quantitative data from TESOL undergraduate students since the selection was based on the researcher's experience and knowledge of the individuals being sampled. Moreover, the participants were already in a specific setting when conducting the research (Cresswell, 2003). On the other hand, a random purposive sampling technique was utilised to get the qualitative data. The researcher used the entire population of 111 pre-service TESOL teachers at the School of Educational Studies; however, only 80 participants handed in completed questionnaires. In terms of gender, 10 per cent of the respondents were males, whereas 90 per cent were females. Regarding year of study, 20 per cent represents the 1 st year students, whilst the 2nd year students represent 22.5 per cent. However, the majority were the 3rd year students with 57.5 per cent. The participants' age ranged as 2.5 per cent of them were 17-19 years old, $66.3 \%$ per cent were 20-22 years old, 30 per cent were 23-25 and 1.3 per cent were 26 and over. In terms of ethnicity, the majority were Malay students with 45 per cent, Chinese students represent 37.5 per cent, and Indians represent 13.8 per cent, whereas others represent 3.8 per cent. Concerning the mother tongue, it was revealed that Malay as a mother tongue constitutes 42.5 per cent, Chinese 37.5 per cent, Tamil 13.8 per cent, English 3.8 per cent and others 2.5 per cent.

\section{Results}

The statistical package of social analysis (SPSS) was employed to analyse the gathered quantitative data by performing both descriptive and inferential statistics. Besides, the interviews were audio-recorded first, transcribed later and finally interpreted in an attempt to accomplish the second objective of the study after listing the frequencies' results from SPSS.

Descriptive statistics was used to explain the properties of the mass of data collected from the respondents, whilst inferential statistics was applied to infer the properties of the population from the properties of the sample (Best \& Kahn, 2006; Gay, et al., 2009). All negatively items were scored in a reverse way in order to conduct the analysis. Pearson moment-product correlation was utilised for the purpose of testing the research only hypothesis. The second objective was attained first by utilising descriptive statistics and next enhancing the answer by transcribing the audio recorded interviews and then interpreting them later. Thus, the qualitative data were employed to consolidate the 
answer especially for the second question.

Descriptive statistics exhibited that the majority of the participants utilised printed dictionary with a per cent of 56.25 , whilst the minority used pocket electronic dictionary with a per cent of 3.75 . Besides, 20 per cent of the students used CD-ROM dictionaries. A similar per cent of students used online dictionary $20 \%$. In terms of the nature of dictionary utilised, it was revealed that the most of the respondents employ monolingual dictionary with a per cent of 47.5 , whilst 27.5 per cent of the students use bilingual dictionary. The least used dictionary among the other types was specialised dictionary with a per cent of 1.25 . Furthermore, a per cent of 32.75 of the students used thesaurus dictionary. A further finding was that 25 per cent of the students viewed CD-ROM dictionary as relevant to their learning needs. It was also revealed that 23 per cent of the respondents regarded it as convenient to carry out. Moreover, a less per cent of 18.3 viewed the reasonable price as their priority, whilst 15.4 per cent considered the number of words as a priority in buying a new CD-ROM dictionary. Besides, a per cent of 10.8 of the students' choices depended on the name of the publisher, whereas a per cent of 7.5 depended on the number of examples. The participants' responses were almost close regarding the best criterion in the CD-ROM dictionary except 4 per cent of them who chose multimedia contents, whilst 25 per cent of them chose speed of use and another similar per cent of 25 was given to ease of use. On the other hand, a bit higher per cent 26 of respondents chose functions.

Like any other statistical tests, Correlation test demands certain assumptions in order to be held. The test of significance is based on the assumption that the distribution of the residual values (i.e., the deviations from the regression line) for the interval (continuous) dependent variable y follows the normal distribution, and that the variability of the residual values is the same for all values of the interval (continuous) independent variable $\mathrm{x}$. This was examined by the scatterplot graph to indicate whether variables are related in a linear or curve line fashion. Other assumptions are the random sampling and the independency of observation from each other (Gravetter \& Wallnau, 2000; Stevens, 1996).

The scatterplot graph (see Figure1) points out that there was a positive linear relation between attitudes and criteria because of the upward trend of the cluster of points. In addition, table 5 shows that there are two interval (continuous) variables which are: criteria and attitudes. Therefore, after meeting the assumptions a Correlation test was conducted to see the significance of the relation between them.

The relationship between pre-service TESOL teachers' attitudes and criteria was investigated using Pearson moment-product correlation coefficient (r). Preliminary analyses were performed to ensure that there was no violation of the assumptions of normality, linearity and homoscedasticity. According to Table 6, there was a moderate positive and significant linear association between pre-service TESOL teachers' attitudes and criteria $(\mathrm{r}$ $(80)=0.395, p=0.00)$. the strength of association $\mathrm{r}^{2}=0.156$ indicating that 15.6 per cent of the variance in attitudes is due to a linear relationship with criteria (Cohen, 1988). From the SPSS output $p=0.00$, since $p<0.01$ so the null hypothesis is rejected. Thus, there is a moderate positive and significant correlation between attitudes towards using CD-ROM dictionaries and criteria.

The second research objective was to explore the learning needs that pre-service TESOL teachers utilise CD-ROM dictionaries for. For the purpose of accomplishing this objective, the study first employed descriptive statistics to find out about the learning needs that pre-service TESOL teachers' use CD-ROM dictionaries for especially after noting that 25 per cent of the respondents considered the relevance of the CD-ROM dictionary to their learning needs as a priority in their buying a new dictionary. Moreover, the results revealed that 31.7 per cent of the students use CD-ROM dictionaries for meaning, 18.8 per cent for spelling, 13.3 per cent for grammar, 12.5 per cent for pronunciation and the same per cent for the number of examples whereas 3.3 per cent of the students use it for phrasal verbs, 5.4 per cent for derivatives and 2.5 per cent for idioms respectively (see Table 7).

The qualitative data were vital especially for consolidating the findings from the questionnaires stage in the study and illuminating some issues that were unanswered by the quantitative data. For the purpose of gaining more in-depth understanding of the learning needs that pre-service TESOL teachers use CD-ROM dictionaries for, interviews become of major importance. Accordingly, 6 students were personally interviewed using almost the same set of questions following the interview protocol. Semi-structured interviews offered the researcher more flexibility in exploring the information needed. All the interviews were audio recorded, transcribed and interpreted later. Essentially, the relationship between quantitative and qualitative methods ensure the trustworthiness of a study's conclusions (Lincoln \& Guba, 2000).

In terms of convenience, 5 interviewees viewed CD-ROM dictionaries as convenient and very helpful except one who complained about the necessity to insert the CD-ROM whenever she wanted to use the pronunciation feature even after the installation considering it as inconvenient since it is time consuming. The 6th interviewee commented: 
have to switch on your computer, you wait...wait, then you insert the CD-ROM, wait for a while, then it's kind of consume a lot of time.

(Int. 01/Y2/F/line20-22)

Similarly, 5 interviewees regarded it as very quick and faster than the printed dictionary as in:

The CD-ROM dictionary, ah firstly it's very convenient; you don't need to flip through the pages as in the printed dictionary. It saves time.

(Int. 02/Y2/F/line42-43)

Consequently, all of the interviewees assured the importance of using CD-ROM dictionaries for the four main language skills (reading, writing, listening and speaking) and the subsidiary skills (grammar, punctuation and pronunciation). Moreover, the interviewee highlighted using it in doing the assignments as in.

I need the dictionary for all the language skills: reading, writing, speaking and listening too. For writing it's useful to use new vocabularies on a piece of paper. For listening also after listening to the correct pronunciation of the words, we can communicate correctly in speaking and the same thing for reading too.

(Int. 04/Y3/F/line54-57)

In spite of the fact that pronunciation got $12.5 \%$ in analysing the data coming in the 3rd position, this important learning need got the interviewees' priority to the extent that one of them described the relevance of this feature to secondary and elementary school students:

I have positive attitudes because it's easy to use, the meanings are accurate. I think also the pronunciation feature is very helpful, how to pronounce the words correctly. I think it should be used at secondary schools especially because of that feature.

(Int. 05/Y3/f/line19-21)

It was also revealed that ease of use was seen by most of the interviewees as the best criterion whereas perceived usefulness of use comes second represented by the speed of use. On the other hand, interviews provided key cues for understanding the reasons behind abandoning using the CD-ROM dictionary by some students represented by the existence of 'a technical error' (Int. 06/Y3/F/line35-36) or:

The system itself because sometimes the program of the CD-ROM dictionary, it's I don't know they're just incompatible with the window system and sometimes it just corrupt.

(Int. 02/Y2/F/line33-34)

In fact, lack of information about the different versions of CD-ROM dictionaries and for different levels was obvious among the interviewees and was the reason behind neglecting it by some and skipping it by others thinking that it does not match university students:

I think it can help secondary and primary school students because it provides details. It may also help university students but myself I prefer online one because it gives me more details. I think that a CD-ROM dictionary is more effective on elementary or secondary school students because they can work with it at home to do homework.

(Int. 05/Y3/F/line12-15)

From an educational perspective, most of the interviewees seemed content that CD-ROM dictionaries can be used in teaching English at schools. An interviewee explained:

Students can gain immediate access; sometimes printed dictionary distracts all the attention. When we want to find a specific word we go and look for other words for example, our attention gets distracted but computer dictionary helps us gain information immediately, strict to the point.

(Int. 03/Y2/F/lines51-54)

Likely, a respondent described:

Students shouldn't only learn from the books but with the help of ICT learning becomes easier and more interesting.

(Int. 05/Y3/F/lines31-32)

Finally, it was obvious based on the responses that all the interviewees have passed through the knowledge, persuasion and decision stages of Roger's theory; however, some have not experienced the implementation and confirmation stages.

\section{Discussion}

After analysing the data and calculating the reliabilities of the instruments, the analyses to both of the quantitative 
and qualitative data were performed. First, findings for the Pearson product-moment correlation coefficient (r) indicated that there was a moderate positive and significant correlation between pre-service TESOL teachers' attitudes towards using CD-ROM dictionaries and criteria after rejecting the first and only research hypothesis. This implies that having positive attitudes towards CD-ROM dictionaries pretends to have moderate positive criteria (perceived usefulness, perceived ease of use, functions and multimedia contents). This result embodied the first novelty of the study since it was different from previous studies in which Hua-Li et al. (2009), Koyama and Takeuchi (2007), Weschler and Pitts (2000), Kusmayanti and Hendryanti (2008) and Arniing and Ziefle (2007) tackled criteria components separately: perceived usefulness, perceived ease of use, functions and multimedia. However, the study after employing the descriptive statistics in analysing the data for criteria components and the exhibition of results exposed almost close per cent for perceived usefulness, perceived ease of use and functions except for multimedia which came last with $4 \%$, it was only then when appeared the need to compute a variable for criteria including all its components for the purpose of exploring any correlation it might have with attitudes. As it was expected, the finding of the Pearson correlation test illustrated a significant relation between criteria and attitudes. Thus, this finding is considered as a novelty to the study because computing criteria variable granted a chance to explore all the components at the same time and not separately like others.

Finally, the second objective of the study was achieved initially by employing descriptive statistics to analyse the data and later by in-depth interviews. The study got rich because of exploring deeper and not just satisfied with the results from the quantitative data. The truth that all know, of seeking the in-depth information to reveal some answers that were partially or fully unanswered by the quantitative data, qualitative data, on the other hand enriches the study since all the interviewees assured that they use the dictionary to do the assignments whether it was the CD-ROM dictionary or online one. Besides, all of the interviewees assured the importance of using the CD-ROM dictionary for the four main language skills (reading, writing, listening and speaking) and the subsidiary skills (grammar, punctuation and pronunciation) simply because from the tapestry of Language Learning, it was noted that we rarely use a single skill when communicating, so it makes sense to focus on more than one skill at a time. They emphasised the importance of the pronunciation feature provided in the CD-ROM dictionary as well. Moreover, they were strongly with using the CD-ROM dictionary in teaching English at schools believing that it facilitates the educational process. However, the interviewees reported the importance of developing the design of the CD-ROM dictionary due to some technical errors that had been encountered by some of them. Furthermore, they suggested that the type of windows should be taken into consideration when designing CD-ROM dictionaries illustrating that they had those times of experiencing some difficulties because the CD-ROM dictionary used by them was incompatible with the window type. Based on the above mentioned, it is worth noting that this study was the first of its kind which employed the qualitative approach to enhance and consolidate the quantitative one. Therefore, both of the qualitative approach and the findings illustrate the second novelty in this study.

\section{Implications}

Basically, the findings in this study might be specific to pre-service TESOL teachers; however, their implications are significant to other educators as well. One of the main barriers to technology implementation noted by the pre-service teachers in this study is the absence of existing PCs in classrooms. It follows that placing computers in schools' labs is not enough for attaining educational change. It is both of principals (i.e. leadership) and teachers sharing the responsibility of introducing ICT forms generally and CD-ROM dictionaries particularly into education which demands equal innovativeness in other aspects of education. Moreover, leaders should provide schools with new ICT-based approaches such as CD-ROM dictionaries and teachers ought to use them in the teaching process to accelerate acquiring the new language. It is therefore essential for leaders to sustain and promote teachers' and as a result learners' attitudes as a prerequisite for deriving the benefits of costly technology initiatives. Since positive attitudes towards using CD-ROM dictionaries usually forecast the future of the CD-ROM dictionary use, policy-makers can make use of teachers' positive attitudes towards CD-ROM dictionaries to better prepare them for incorporating CD-ROM dictionaries in their teaching practices.

Although CD-ROM dictionaries save time in looking up the meanings for new vocabularies that encounter learners in their attempt to acquire English as a second language, a quite good number of learners are still not familiar with this relevant type of dictionaries or do not have a command over using them represented in the lack of skills or knowledge about the different versions and levels available for each particular need. Thus, this study has also some implications to teachers, especially novice ones and students nevertheless, since they can benefit via introducing new vocabularies in the lessons avoiding falling in embarrassing situations of not knowing the meaning of a certain vocabulary or how to pronounce it correctly.

Furthermore, findings also have some implications for pre-service TESOL course curriculum designers to signify the importance of implying CD-ROM dictionaries especially in the integration of ICT in teaching and learning 
English language as one of the crucial topics in the course. Demonstrations for the different versions of CD-ROM dictionaries and illustrations on the available online activities from Oxford website ought to be clarified. Given the knowledge that pre-service TESOL teachers can become members in Oxford teachers' club is very beneficial for their future career by equipping them with the different services and being updated with the latest lessons and materials regarding teaching English out of charge. Besides, the findings have confirmed the theoretical framework of the study, which was drawn from Diffusion of Innovations' theory by Rogers (1995) and TAM model by Davis (1986, 1989), in a sense that perceived usefulness, perceived ease of use and multiple functions were the strong determinants of the actual and successful utilisation of technology.

Finally, the results have implications that device developers should focus on improving the design of the CD-ROM dictionary taking into consideration the following two barriers encountered by the students. One of which represents the necessity to insert the CD-ROM whenever the user needs to listen to the pronunciation of a particular word whereas the second barrier resembles the compatibility of the CD-ROM dictionary to different windows types. Hence, if device-developers want teachers to utilise CD-ROM dictionaries in the process of teaching English via technology integration, they have to find ways to overcome the barriers perceived by the pre-service teachers.

\section{References}

Arning, K., \& Ziefle, M. (2007). Understanding age differences in PDA acceptance and performance. Computers in Human Behavior, 23(6), 2904-2927. http://dx.doi.org/j.chb.2006.06.005

Barlett, M. S. (1954). A note on the multiplying factors for various chi square approximations. Journal of the Royal Statistical Society, 16(Series B), 296-298.

Best, J. W., \& Kahn, J. V. (2006). Research in Education (10th ed.). Needham Heights, MA: Pearson/Allyn and Bacon.

Borg, S. (2007). Language Teacher Research in Europe. Alexandria, VA Tesol Quarterly.

Cohen, J. (1988). Statistical power analysis for the behavioral sciences (2nd ed.). Hillsdale, New Jersey: Routledge.

Cresswell, J. W. (2003). Research Design: Qualitative, Quantitative and Mixed Methods Approaches (2nd ed.). Thosands Oaks: Sage Publications.

Davis, F. D. (1986). A technology acceptance model for empirically testing new end-user information systems: Theory and results. Unpublished Doctorial dissertation, Massachusetts Institute of Technology, Massachusetts.

Davis, F. D. (1989). Perceived usefulness, perceived ease of use, and user acceptance of information technology. MIS Quarterly, 13(3), 319-340.

De-Schryver, G. M. (2003). Lexicographers' Dreams in the Electronic-Dictionary Age. International Journal of Lexicography, 16(2), 143-199. http://tshwanedje.com/publications/dreams.pdf

De-Schryver, G. M., \& Joffe, D. (2004). On How Electronic Dictionaries are Really Used. Paper presented at the Eleventh EURALEX COMPUTATIONAL LEXICOGRAPHY AND LEXICOLOGY. International Congress, Euralex 2004, Lorient, France. http://tshwanedje.com/publications/euralex2004-LOGS.pdf

Dongsheng, T., Jiahua, C., Peide, S., \& Yaohua, W. (2005). A Bartlett Type Correction for Rao's Score Test in Cox Regression Model. The Indian Journal of Statistics, 67(4), 722-735.

Gay, L. R., Mills G. E., \& Airasian, P. (2009). Educational Research: Competencies for Analysis and Applications (9th ed.). New Jersey: Pearson Education, Inc, Upper Saddle River.

Graddol, D. (2006). English Next. pp. (10). Available from http://www.britishcouncil.org/learning-research-english-next.pdf

Gravetter, F. J., \& Wallnau, L. S. (2000). Statistics for the behavioral sciences (5th ed.). Belmont, CA: Wadsworth.

Hua-Li, J., Sandnes, F. E., Law, K. M. Y., Yo-Ping, H., \& Yueh-Min, H. (2009). The Role of Electronic Pocket Dictionaries as an English Learning Tool among Chinese Students. Journal of Computer Assisted Learning, 25(6), 503-514.

Kaiser, H. (1970). A second generation Little Jiffy. Psychometrika. (Vol. 35, pp. 401-415). http://dx.doi.org/10.1007/BF02291817

Kaiser, H. (1974). An index of factorial simplicity. Psychometrika. (Vol. 39, pp. 31-36). http://dx.doi.org/10.1007/BF02291575

Koyama, T., \& Takeuchi, O. (2007). Does look-up Frequency Help Reading Comprehension of EFL Learners? Two Empirical Studies of Electronic Doctionaries. CALICO Journal, 25(1), 110-125. 
Kusmayanti, I. N., \& Hendryanti, R. (2008). Electronic Dictionary as EFL Media for Indonesian English Teachers and Students of Junior High Schools: Efficacious or Futile. Paper presented at the Proceedings of CLaSIC 2008.

Le Cornu, R., \& Ewing, R. (2008). Reconceptualising professional experiences in pre-service teacher educationyreconstructing the past to embrace the future. Teaching and Teacher Education, 24, 1799-1812.

Lincoln, Y. S., \& Guba, E. G. (2000). Paradigmatic controversies, contradictions, andemerging confluences. In N. K. D. Y. S. Lincoln (Ed.), Handbook of Qualitative Research (Vol. $2^{\text {nd }}$ ). Thousand Oaks: Sage Publications.

Liou, H. C. (2000). The Electronic Bilingual Dictionary as a Reading Aid to EFL Learners: Research Findingd and Implications. Computer Assisted Language Learning, 13(4), 467-476. http://dx.doi.org/10.1076/0958-8221(200012)13:4-5;1-E;FT467

Moore, J. (2005). Oxford Collocation Dictionary for Students of English.

Nguyen, L. V. (2008). (The Pros. and Cons. of Using Information and Communication Technology in Language Education). THE GOOD, THE BAD AND THE ICT.

Nunnally, J. O. (1978). Psychometric Theory. New York: McGraw-Hill.

Pallant, J. (2005). SPSS SURVIVAL MANUAL A step by step guide to data analysis using SPSS for Windows (Version 12). Crows Nest NSW, Australia: Allen \& Unwin.

Pasfield-Neofitou, S. (2009). Paper, Electronic or Online? Different Dictionaries for Different Activities. Babel, 43(2), 12-18.

Rogers, E. M. (1995). Diffusion of Innovations (4th ed.). New York: The Free Press.

Sevim İ., İlke E., \& Saracaloğlu, A. S. (2003). The relation between Students' Attitudes toward Foreign Language and Foreign Language Achievement. Paper presented at the International Conference Dokuz Eylül. Approaches to the Study of Language and Literature.

Shelly, G. B., Cashman, T. J., Gunter, R. E., \& Gunter, G. A. (2004). Teachers discovering computers—integrating technology into the classroom. Boston, MA: Thomson Course Technology.

Sobkowiak, W. (2002). The Challenge of Electronic Learners' Dictionaries. Paper presented at the IATEFL Computer Special Interest Group, Poland.

Stevens, J. (1996). Applied multivariate statistics for the social sciences ( ${ }^{\text {rd }}$ ed). Mahway, NJ: Lawrence Erlbaum.

Tan, K. H. (2003). Sense Differentiation in Print and Electronic Dictionaries: A Survey of Test Instruments. Paper presented at the 3rd IEEE International Conference on Advanced Learning Technologies (ICALT'03).

Tan, K. H., \& Woods, P. C. (2008). Media-Related Or Generic-Related Features In Electronic Dictionaries: Learners' Perception And Preferences. GEMA Online Journal of Language Studies, 8(2), 1-17.

Tinio, V. L. (2003). ICT in Education. Retrieved 5 December, 2010, from UNDP-APDIP: http://www.apdip.net/publications/iespprimers/eprimer-edu.pdf

Weschler, R., \& Pitts, C. (2000). An Experiment Using Electronic Dictionaries with EFL Students. The Internet TESL Journal, VI(8). [Online] Available: http://iteslj.org/Articles/Weschler-ElectroDict.html (Retrieved 10 December, 2009).

Winkler, B. (2001). English Learners' Dictionaries on CD-ROM as Reference and Language Learning Tools. ReCALL, 13(2), 191-205. http://dx.doi.org/10.1017/S0958344001000520a

Wright, J. (1998). Dictionaries. OUP Oxford.

Yoon, H., \& Hirvela, A. (2004). ESL Student Attitudes toward Corpus Use in L2 Writing. Journal of Second Language Writing, 13, 257-283. [Online] Available: http://www.u.arizona.edu/ karaj/pages/Reviews/YH2004.pdf (Retrieved 30 December, 2009)

Table 1. Case Processing Summary

\begin{tabular}{|l|l|l|l|}
\hline \multicolumn{2}{|l|}{} & N & $\%$ \\
\hline Cases & Valid & 30 & 100.0 \\
\hline & Excluded(a) & 0 & .0 \\
\hline & Total & 30 & 100.0 \\
\hline
\end{tabular}


Table 2. Reliability Statistics for Attitude

\begin{tabular}{|l|l|}
\hline Cronbach's Alpha & No. of Items \\
\hline .878 & 37 \\
\hline
\end{tabular}

Table 3. KMO and Bartlett's Test (Criteria)

\begin{tabular}{|l|l|l|}
\hline $\begin{array}{l}\text { Kaiser-Meyer-Olkin } \\
\text { Adequacy. }\end{array}$ & .606 \\
\hline \begin{tabular}{l} 
Bartlett's Test of $\begin{array}{l}\text { Seasure of Sampling } \\
\text { Sphericity }\end{array}$ \\
\cline { 2 - 3 }
\end{tabular} & Approx. Chi-Square & 80.128 \\
\cline { 2 - 3 } & Sig. & 15 \\
\hline
\end{tabular}

Table 4. KMO and Bartlett's Test (Attitudes)

\begin{tabular}{|c|c|c|}
\hline \multicolumn{2}{|l|}{$\begin{array}{l}\text { Kaiser-Meyer-Olkin } \\
\text { Adequacy. }\end{array}$} & .813 \\
\hline \multirow{2}{*}{$\begin{array}{c}\text { Bartlett's Test of } \\
\text { Sphericity }\end{array}$} & Approx. Chi-Square & 968.336 \\
\cline { 2 - 3 } & df & 190 \\
\cline { 2 - 3 } & Sig. & .000 \\
\hline
\end{tabular}

Table 5. Descriptive Statistics

\begin{tabular}{|c|c|c|c|}
\hline & Mean & Std. Deviation & $\mathrm{N}$ \\
\hline Criteria & 2.9688 & .37673 & 80 \\
\hline Attitudes & 3.3806 & .47611 & 80 \\
\hline
\end{tabular}

Table 6. Pearson correlation coefficients

\begin{tabular}{|l|l|c|c|}
\hline & & Criteria & Attitudes \\
\hline Criteria & Pearson Correlation & 1 & $.395(* *)$ \\
\hline & Sig. (2-tailed) & & .000 \\
\cline { 2 - 4 } & N & 80 & 80 \\
\hline Attitudes & Pearson Correlation & $.395(* *)$ & 1 \\
\hline & Sig. (2-tailed) & .000 & \\
\cline { 2 - 4 } & $\mathrm{N}$ & 80 & 80 \\
\hline
\end{tabular}

** Correlation is significant at the 0.01 level (2-tailed).

Table 7. Learning Needs

\begin{tabular}{|c|c|c|c|c|c|}
\hline & & Frequency & Per cent & Valid Per cent & Cumulative Per cent \\
\hline \multirow[t]{9}{*}{ Valid } & Spelling & 45 & 18.8 & 18.8 & 18.8 \\
\hline & Meaning & 76 & 31.7 & 31.7 & 50.5 \\
\hline & Grammar & 32 & 13.3 & 13.3 & 63.8 \\
\hline & Pronunciation & 30 & 12.5 & 12.5 & 76.3 \\
\hline & Usage (Examples) & 30 & 12.5 & 12.5 & 88.8 \\
\hline & Phrasal verbs & 8 & 3.3 & 3.3 & 92.1 \\
\hline & $\begin{array}{l}\text { Derivatives, } \\
\text { Compounds }\end{array}$ & 13 & 5.4 & 5.4 & 97.5 \\
\hline & Idioms & 6 & 2.5 & 2.5 & 100 \\
\hline & Total & 240 & 100.0 & 100.0 & \\
\hline
\end{tabular}




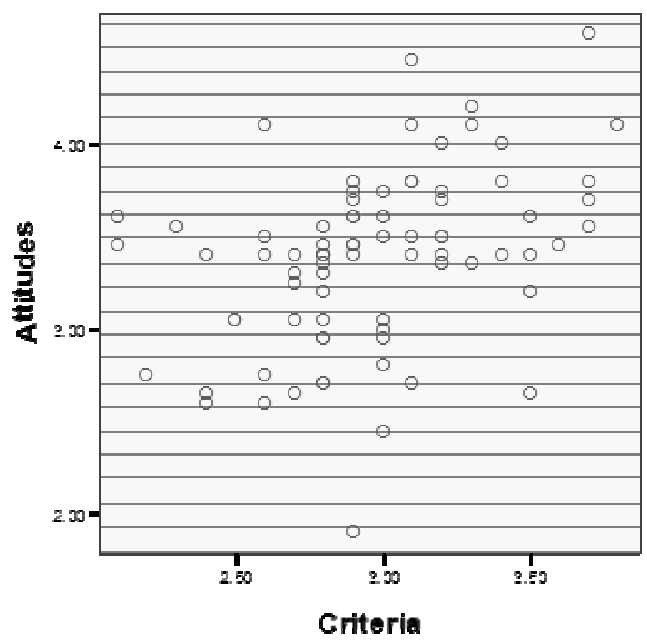

Figure 1. Scatterplot graph of Attitudes and Criteria 